\title{
Canine benign hyperplasia prostate on male pug dog
}

\author{
Zulfa Ichsanniyati R.Ciwi Fadhlillah ${ }^{1}{ }^{*}$, I Nengah Yogiswari $^{1}$, Siti Zaenab ${ }^{1}$, \\ Deni Noviana $^{1,2,3}$, Sukmasari Arifah ${ }^{1}$ \\ ${ }^{1}$ My Vets Animal Clinic Jakarta \\ ${ }^{2}$ Division of Radiology and Surgery, Faculty of Veterinary Medicine, IPB University, Bogor \\ ${ }^{3}$ Veterinary Teaching Hospital, Faculty of Veterinary Medicine, IPB University, Bogor
}

\begin{abstract}
An 9-years-old male pug was examined for stranguria and letargic in one week. The dog has no testicles as the owner claimed that the dog had been castrated a few years ago. Abdominal palpation shows bladder retention filled with urine but no blockage was found. Urine sedimentation contained blood and few unknown crystal. Hematology showed mild anemia and leukocytosis while blood chemistry only found mild hyperglobulinemia. Radiography showed prostate enlargement. U1trasound examination was showing mild nephrolithiasis, cystitis and prostatic enlargement. Diagnosis of benign prostate hyperplasia is suspected but doubtful because the animal has been castrated. Differential diagnose was prostatic cysts, infection and cancer. The dog received finasteride $1 \mathrm{mg} / \mathrm{kg}$ twice a day orally for 60 days and antibiotic. Urine catheter was temporarily installed to evacuate urine twice a day. Post treatment ultrasound was performed 20 days later and showed evident involution of prostate sizes. An enlarge irregular testicle was also found in right dorsolateral of bladder. Monorchid castration was performed at 60 days of finasteride. The dog was diagnosed with monorchid induce benign prostate hyperplasia from the radiography and ultrasonography. The prostate size was reduced after finasteride administration.
\end{abstract}

\section{Keywords:}

canine benign prostate hyperplasia, monorchid, finasteride, pug dog

\section{- INTRODUCTION}

The prostate gland is a bilobed, oval gland located in the pelvic cavity of adult dogs through which passes the urethra and the vas deferens, where the sperm are carried to the urethra.The prostate is stimulated by the testosterone produced by testicles and converted into dihydrotestosterone (DHT) by the enzyme $5 \alpha$-reductase (Leis-Filho \& FonsecaAlves 2018).

Castrated dogs lack testosterone and consequently DHT will lead to the prostate to a state athropy (Adel \& Khadidja 2017). Canine prostatic disorders include benign prostatic hyperplasia (BPH), prostatic squamous metaplasia, prostatic cysts, prostatic inflammation, prostatic abscess, prostatic neoplasia (Adel \& Khadidja 2017). Prostatic neoplasia is androgen independent so it may affectingboth castrated and non-castrated animal (Adel \& Khadidja 2017; Paclikova et al. 2006).

All prostatic disorders generally observed in dog older than 6 years old, appear as enlargement of the glands that suppress the surrounding organs namely the rectum and urethra. Clinical signs may range from stranguria-dysuria, fecal tenesmus, urethral discharge, and systemic symptoms including depression, lethargy, fever, anorexia, pain and weight loss for prostatic neoplasia. Diagnose is done by taking anamnesis of castration history and the main com- plaint about the presence of urination and defecation disorder and observed clinical symptoms as mentioned previously (Adel \& Khadidja 2017; Paclikova et al. 2006). Bladder retention may be found in abdominal palpation, and protrusion of the prostate gland will be palpated on ventral rectal palpation. Hematology to evaluate presence of inflammation and infection from leukocytosis with left shift neutrophilia in acute or within normal in chronic disease while biochemical parameters are not specific in patients without systemic alteration. Urinalysis is performed to evaluate the presence of blood, leukocytes, urinary sediment and overall epithelial cells (Adel \& Khadidja 2017; Paclikova et al. 2006).

Radiology is the first-choice method in evaluation of position, size and outer surface of the prostate. The prostate is considered enlarged when the prostatic diameter, as visualized on the lateral radiographic view, is greater than $70 \%$ of the pubicsacral promontory distance (Feeney et al. 1987). The more prostate gland grows; it subsequently obturates pelvic inlet compromising distal colon and rectum, often clearly visible on the $\mathrm{x}$-rays. Thoracic radiography is necessary if metastatic prostatic neoplasia is suspected (Paclikova

Diterima: 28-06-2019 | Direvisi: 03-08-2019 | Disetujui: 10-08-2019 (C) 2019 CC-BY-SA. Ini adalah artikel Open Access yang didistribusikan berdasarkan ketentuan dari Creative Commons Attribution ShareAlike 4.0 International License (https://creativecommons.org/licenses/by-sa/4.0/). 
et al. 2006). Ultrasound examination marked by increase hyperechogenosity and volume of prostatic gland as well to find testicle in case of cryptorchid (Yehia \& Salem 2015). Biopsy may need to perform if no response with the primary treatment.

Finasteride is 5-alpha reductase inhibitory as primary medication $1 \mathrm{mg} / \mathrm{kg} / \mathrm{day}$, po for $16-21 \mathrm{wk}$ to reduce prostatic hyperthropy and resolve clinical sign. Antibiotic and anti inflammation would be necessary if there is sign of infection and inflammation. Castration should be recommended for any prostatic disorders mainly BPH (Adel \& Khadidja 2017; Paclikova et al. 2006). Euthanasia should be considered for metastatic prostatic neoplasia as no curable treatment available (Adel \& Khadidja 2017; Paclikova et al. 2006).

\section{- CASE REPORT}

An 9-years-old male pug dog was examined for stranguria and lethargic in one week. The dog has no testicles as the owner claimed that the dog had been castrated a few years ago. Abdominal palpation shows bladder retention filled with urine but no blockage was found. Urine sedimentation contained blood and few unknown crystal. Hematology showed mild anemia and leukocytosis while blood chemistry only found mild hyperglobulinemia. Radiography showed prostate enlargement (Figure 1).

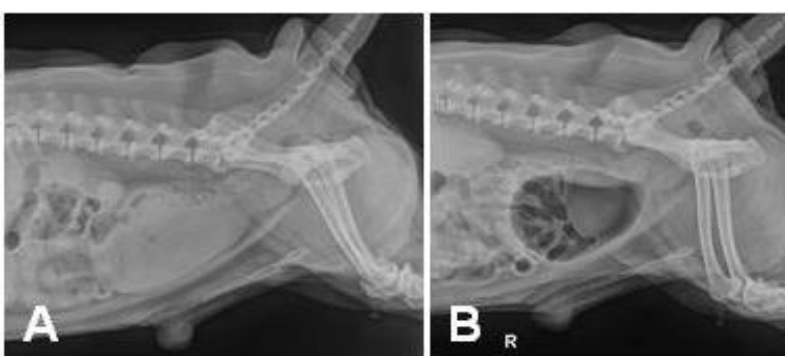

Figure 1 Right latero-lateral plain (A) and negative contrast bladder-urethral (B) radiography showed prostatic enlargement with no cystitis and urethral obstruction.

Ultrasound examination was showing cystitis and prostatic enlargement (Figure 2A). Diagnosis of benign prostate hyperplasia is suspected but doubtful because the animal has been castrated. Differential diagnose was prostatic cysts, infection and cancer. The dog received finasteride 1 $\mathrm{mg} / \mathrm{kg}$ twice a day orally for 60 days and antibiotic. Urine catheter was temporarily installed to evacuate urine twice a day. Post treatment ultrasound 20 days after treatment showed evident of prostate sizes involution (Figure 2B).
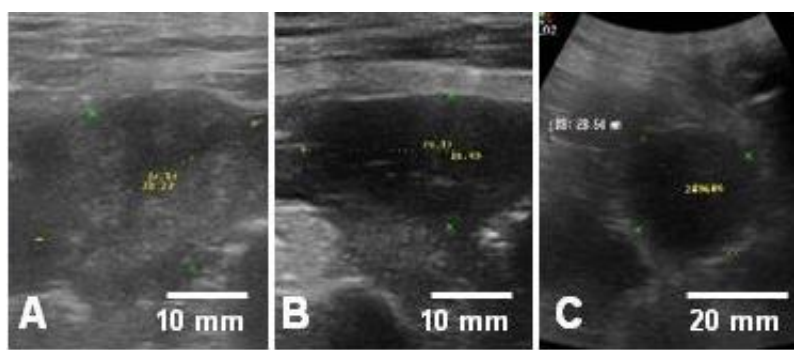

Figure 2. Ultrasound image of prostatic enlargement (A), ultrasound image of involution prostate after 32 days finasteride (B), and ultrasound image of monorchid testicle (C).

An enlarge irregular testicle was also found in right dorsolateral of bladder (Figure 2C). Monorchid castration was performed at 60 days of finasteride. Ultrasound checkup 2 month after the surgery shows no abdominal organ abnormality.

\section{- CONCLUSION}

The dog was diagnosed with monorchid induce benign prostate hyperplasia from the radiography and ultrasonography. The prostate dog size was reduced after finasteride administration.

\section{- AUTHOR INFORMATION}

\section{Corresponding Author}

*ZIRCF: zulfa.koshka@gmail.com

My Vets Animal Clinic, Jakarta, Indonesia

\section{Author Contributions}

These authors contributed equally

\section{- REFERENCES}

Adel A, Khadidja M. 2017. Canine prostatic disorders. Veterinary Medicine-Open Journal. 2(3):83-90.

Feeney DA, Johnston GR, Klausner JS, Perman V, Leininger JR, Tomlinson MJ. 1987. Canine prostatic disease--comparison of radiographic appearance with morphologic and microbiologic findings: 30 cases (1981-1985). Journal of the American Veterinary Medical Association. 190(8):1018-1026.

Leis-Filho AF, Fonseca-Alves CE. Anatomy, histology, and physiology of the canine prostate gland. InVeterinary Anatomy and Physiology 2018 Nov 5. IntechOpen.

Paclikova K, Kohout P, Vlasin M. 2006. Diagnostic possibilities in the management of canine prostatic disorders. Veterinarni medicinapraha-. 51(1):1-13.

Yehia SG, Salem NY. 2015. Ultrasonographic abnormalities in canine urinary and prostatic affections. Res. J. Vet. Pract. 4(3):93-98. 